addition to smoking. The occupational variation in risk of bladder cancer is small when adjusted for smoking.

\section{EARLY MARKERS OF CARDIOVASCULAR DISEASE ARE ASSOCIATED WITH OCCUPATIONAL EXPOSURE TO POLYCYCLIC AROMATIC HYDROCARBONS}

${ }^{1}$ Ayman Alhamdow* ${ }^{*}{ }^{2}$ Christian Lindh, ${ }^{1,2}$ Maria Albin, ${ }^{1}$ Per Gustavsson, ${ }^{2}$ Håkan Tinnerberg,
${ }^{1,2}$ Karin Broberg. ${ }^{1}$ Karolinska Institutet, Stockholm, Sweden; ${ }^{2}$ Lund University, Lund, Sweden

10.1136/oemed-2018-ICOHabstracts. 1057

Introduction Occupational exposure to polycyclic aromatic hydrocarbons (PAH) from soot is common and has been associated with increased risk of cardiovascular disease (CVD); the association, however, has only been indicated, not established. Our aim was to investigate occupational exposure to PAH and early markers of CVD.

Methods A cross-sectional study of 151 chimney sweeps and 152 controls, all males, from Sweden was conducted between 2011-2015. Participants answered a questionnaire and gave blood and urine samples. Urinary PAH metabolites were measured using LC-MS/MS: 1-hydroxypyrene (1-OH-PYR), 2hydroxyphenanthrene (2-OH-PH), 3-hydroxybenzo[a]pyrene (3-OH-BaP), and 3-hydroxybenzo[a]anthracene (3-OH-BaA). Blood pressure (BP) and serum biomarkers were measured (Creactive protein, homocysteine, gamma-glutamyltransferase, cholesterol, HDL, LDL, and triglycerides), to estimate the risk of CVD.

Results Chimney sweeps had up to 7-fold higher concentrations of PAH metabolites in urine than controls $(p<0.001)$ : median concentrations (adjusted for specific gravity) for 1$\mathrm{OH}-\mathrm{PYR}, 2-\mathrm{OH}-\mathrm{PH}, 3-\mathrm{OH}-\mathrm{BaP}$, and $3-\mathrm{OH}-\mathrm{BaA}$ were $0.56 \mu \mathrm{g} /$ $\mathrm{L}, \quad 0.78 \mu \mathrm{g} / \mathrm{L}, \quad 4.75 \mathrm{ng} / \mathrm{L}$, and $6.28 \mathrm{ng} / \mathrm{L}$, respectively. $\mathrm{PAH}$ metabolites correlated positively with the amount of soot sweeping as a percentage of total work $(p<0.001)$. Chimney sweeps had increased homocysteine, cholesterol, and HDL $(\beta=3.4 \mu \mathrm{mol} / \mathrm{L}, 0.43 \mathrm{mmol} / \mathrm{L}$, and $0.13 \mathrm{mmol} / \mathrm{L}$, respectively, $\mathrm{p} \leq 0.003$, adjusted for age, BMI, and smoking). 2-OH-PH, 3$\mathrm{OH}-\mathrm{BaP}$, and 3-OH-BaA were positively associated with diastolic BP in chimney sweeps $(\mathrm{p}<0.044$, adjusted for age, BMI, and smoking).

Conclusions Working with soot resulted in clear exposure to $\mathrm{PAH}$, and in turn, an elevated risk for CVD. These findings indicate the need to raise awareness of protective measures that can decrease PAH exposure during work and in the general environment.

\section{OCCUPATIONAL ACCIDENTS REPORTED WITHIN THE FORENSIC MEDICINE DEPARTMENT}

D Lahlou*, I El Amri, B Benali, A Chbani, A Elkholti. Casablanca Faculty of medicine and pharmacy, Hassan II university, Morocco

\subsection{6/oemed-2018-ICOHabstracts. 1058}

Introduction Professions in health care settings are characterised as having a high professional risk, in addition tohealth care workers, all occupations are carried out with specific constraints, exposing personnel to several risks, due to accidents involving exposure to biological products, physical nuisance, chemical toxicity and stress.
Materials and methods Our work consists of a retrospective study of 119 cases of occupational accidents declared by staff (3684 employees) of the Ibn Rochd University Hospital in Casablanca, over a period of 3 years (between January 2010 and December 2012).

Results Ninety women and twenty ninemen were enumerated, with a sex ratio of 0.32 .The average age was 45.58 years, with extremes of 23 to 60 years.

Nurses and nursing assistants represent $42,01 \%$ of the cases, followed by service agents (31\%), then doctors $(15,12 \%)$. Administrative personnel remainsas the least the exposed category $(6,72 \%)$.

The most frequent accidents are related to falls $(52,08 \%)$, followed by blood exposure (18,48\%), while musculoskeletal disorders come far after with a percentage of $3.36 \%$. The temporary work disability, stands between 3 days and 3 months, with a prolongation that can go up to 12 months. Thenumber of patient who had a permanentpartial disability was 28 , with rates varying from $2 \%$ to $18 \%$. None of them needed a job change orreclassification.

Conclusion Hospital staff is exposed to a number of risks, this requires taking somenecessarymeasures to ensure the safety and protect the health of healthcare workers, taking as a base general principles of prevention.

\section{SELF-DETERMINING MEDICAL LEADERSHIP NEEDS OF OCCUPATIONAL MEDICINE PHYSICIANS - A STUDY THAT CAN RESHAPE THE MEDICAL LEADERSHIP TRAINING}

1,2,3Prosenjit Giri* ${ }^{3}{ }^{3}$ Jill Aylott, ${ }^{4}$ Karen Kilner. ${ }^{1}$ Sheffield Teaching Hospitals Nhs Trust, Worksop, UK; ${ }^{2}$ Sheffield University, UK; ${ }^{3}$ International Academy of Medical Leadership, Dronfield, Derbyshire, UK; ${ }^{4}$ Centre for Leadership in Health and Social Care, Sheffield Hallam University, Sheffield, UK

\subsection{6/oemed-2018-ICOHabstracts. 1059}

Introduction Physician leadership, irrespective of hierarchy, is an integral part of delivering complex modern-day healthcare which thrives on quality improvement and efficiency savings. Doctors' participation in Medical Leadership however remains fragmented and patchy as has been their leadership training. Absence of empirical research in designing strategies to engage and motivate doctors and validated leadership qualities assessment instruments may have compounded the problem further. Methods This national study, facilitated by the Faculty of Occupational Medicine of the UK (FOM), explored factors that motivate the UK-based Occupational Medicine Physicians (OHPs) to engage in leadership roles alongside assessment of their leadership competency and training needs by framing an inquiry within Self-Determination Theory using the 7 domain National Health Service Leadership Academy self-assessment tools on a web-based platform. The data were analysed using descriptive statistics and simple inferential methods.

Results 25\% (250/1000) of the UK-based FOM $(n=1000)$ members participated. OHPs were open about reporting their leadership strengths (mean score; $4.26 / 8$ across 7 domains; highest in personal qualities; 5.77/8 and lowest in Creating the Vision; 2.73/8). Irrespective of personal level of competency, they universally recognised the need for life-long leadership training. Experience of management role (6 domains; $\mathrm{p}<0.05)$ was identified as the single most influencing factor behind a doctor's confidence. In multivariate regression, management experience accounted for the usefulness of leadership 